BULLETIN Bulletin hispanique

HISPANIQUE Université Michel de Montaigne Bordeaux

116-1 | 2014

Varia

\title{
Ensayo de una bibliografía general de Francisco Umbral (1932-2007)
}

José Luis Campal Fernández

\section{(2) OpenEdition}

Journals

Edición electrónica

URL: http://journals.openedition.org/bulletinhispanique/2898

DOI: 10.4000/bulletinhispanique.2898

ISSN: $1775-3821$

Editor

Presses universitaires de Bordeaux

Edición impresa

Fecha de publicación: 1 junio 2014

Paginación: 469-485

ISBN: 978-2-86781-931-5

ISSN: 0007-4640

Referencia electrónica

José Luis Campal Fernández, «Ensayo de una bibliografía general de Francisco Umbral (1932-2007)

», Bulletin hispanique [En línea], 116-1 | 2014, Publicado el 01 junio 2014, consultado el 23 mayo 2020

URL : http://journals.openedition.org/bulletinhispanique/2898; DOI : https://doi.org/10.4000/

bulletinhispanique.2898

Este documento fue generado automáticamente el 23 mayo 2020.

Tous droits réservés 


\title{
Ensayo de una bibliografía general de Francisco Umbral (1932-2007)
}

\author{
José Luis Campal Fernández
}

1 La obra de Francisco Umbral, seudónimo empleado por el escritor Alejandro Francisco Pérez Martínez, se cerró el martes 28 de agosto de 2007 en el hospital de Boadilla del Monte (Madrid), setenta y cinco años después de que hubiera venido al mundo, un 11 de mayo de 1932, en el hospital de la maternidad de la capital de España ${ }^{1}$.

2 Tras una infancia que transcurre por tierras de Laguna de Duero, Palencia, León y Valladolid, y en la que no se libró de una infección tuberculosa, arranca su vida laboral como ordenanza de una entidad bancaria. Emprende luego Umbral una frenética actividad periodística que conoce sus compases iniciales en los rotativos $E l$ Norte de Castilla y El Diario de León, ciudad esta en la que probó fortuna en el medio radiofónico y donde verá premiado, en 1961, su cuento «La paloma en el negociado», género en el cual cosechará, por esta época, varias distinciones más. Su traslado a Madrid, en la primera mitad de la década de los 60 , supone el espaldarazo definitivo a su indesmayable y productiva fecundidad, así como a su constante presencia en la columna de prensa, de la que nunca se apeará.

3 La obra literaria umbraliana -territorio donde los límites se entrecruzan, combinan y difuminan- se distingue, según Ignacio Soldevila Durante, por su carácter «elegíaco y de distanciación irónica de la realidad». En el dominio de los múltiples registros expresivos del español y sus variantes coloquiales, que amasó con tierna insolencia y un toque de lírica urbana, el escritor ha ido incardinando, en una construcción literaria de su propia autobiografía emocional, sus temas recurrentes: guerra civil y posguerra, las caras de Madrid, el lumpen, la memoria personal, el sexo, el oficio de escritor, la relación materna, etc.

4 Aunque no logró asiento en la Real Academia Española cuando fue propuesto a ocupar alguna de sus vacantes, Umbral atesoró algunos de los más relevantes y elevados reconocimientos del mundo cultural hispánico, ya que cuenta en su haber con los premios «Gabriel Miró» (1964), «Carlos Arniches» (1975), «Nadal» (1975), «César González-Ruano» (1980), «Mariano de Cavia» (1990), «Antonio Machado» (1990), 
«Premio Nacional de la Crítica» (1991), «Francisco Cerecedo» (1995), «Príncipe de Asturias de las Letras» (1996), «Fernando Lara» (1997), «Premio Nacional de las Letras Españolas» (1997), «Cervantes» (2000) y «Mesonero Romanos» (2003), entre otros.

Ofrezco seguidamente una tentativa de aproximación o relación de las obras (tanto volúmenes individuales y colectivos como plaquettes o separatas de las que tuviera constancia) publicadas durante su fértil carrera por Francisco Umbral, una muestra de conjunto de 264 fichas ordenadas cronológicamente en doce apartados, sumamente indicativos de las áreas genéricas que el escritor tocó. Me ciño a la primera edición, eludiendo consignar todas las ediciones, reediciones o traducciones que cada pieza registró, así como los artículos en periódicos y revistas que no fueran recopilados por el autor en libros autónomos.

\section{Novela y novela corta}

1) Balada de gamberros, Madrid, Ediciones Alfaguara, Colección «La novela popular»,

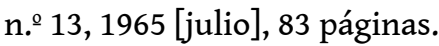

2) Travesía de Madrid, Madrid, Ediciones Alfaguara, Colección «Alfaguara literaria», n. 7, 1966 [junio], 309 páginas.

3) Si hubiéramos sabido que el amor era eso, Madrid, Editorial Literoy, Colección «Voz del tiempo», n. 3, 1969 [enero], 224 páginas.

4) Las europeas, Andorra la Vella-Barcelona, Editorial Andorra, Colección «Biblioteca Valira», n.ํ 6, 1970, 213 páginas. Prólogo de José Domingo.

5) El Giocondo, Barcelona, Editorial Planeta, Colección «Autores españoles e hispanoamericanos», 1970 [octubre], 243 páginas.

6) Los males sagrados, Barcelona, Editorial Planeta, Colección «Biblioteca universal Planeta/Fábula», n.ำ 22, 1973 [junio], 162 páginas.

7) Retrato de un joven malvado (Memorias prematuras), Barcelona, Ediciones Destino, Colección «Áncora y delfín», n.ํ4 435, 1973 [noviembre], 218 páginas.

8) Mortal y rosa, Barcelona, Ediciones Destino, Colección «Áncora y delfín», n. 468, 1975 [mayo], 206 páginas.

9) Las respetuosas, Barcelona, Editorial Planeta, Colección «Autores españoles e hispanoamericanos», 1976 [enero], 257 páginas.

10) Las ninfas, Barcelona, Ediciones Destino, Colección «Áncora y delfín», n.ำ 481, 1976 [febrero], 248 páginas.

11) Los amores diurnos, Barcelona, Editorial Kairós, 1979 [marzo], 223 páginas.

12) Los helechos arborescentes, Barcelona, Editorial Argos Vergara, Colección «Las cuatro estaciones», 1980 [junio], 238 páginas.

13) A la sombra de las muchachas rojas (Crónicas marcianas de la transición), Madrid, Editorial Cátedra, Colección «Novela Cátedra», 1981 [junio], 189 páginas.

14) La bestia rosa, Barcelona, Tusquets Editores, Colección «La sonrisa vertical/ Biblioteca del erotismo», n. 28, 1981 [diciembre], 195 páginas.

15) Las ánimas del purgatorio, Barcelona, Ediciones Grijalbo, Colección «Narrativa 80», 1982 [marzo], 209 páginas.

16) Las giganteas, Esplugues de Llobregat (Barcelona), Plaza \& Janés Editores, Colección «Plaza \& Janés Literaria», 1982 [septiembre], 234 páginas.

17) El hijo de Greta Garbo, Barcelona, Ediciones Destino, Colección «Áncora y delfín», n. ${ }^{\circ}$ 568, 1982 [noviembre], 191 páginas. 
18) La belleza convulsa, Barcelona, Editorial Planeta, Colección «Narrativa», n.․ㄹㄹ, 1985 [octubre], 183 páginas.

19) Pío XII, la escolta mora y un general sin un ojo, Barcelona, Editorial Planeta, Colección «Autores españoles e hispanoamericanos», 1985 [noviembre], 236 páginas.

20) Sinfonía borbónica, Barcelona, Ediciones Destino, Colección "Áncora y delfín", n.. 606,1987 [septiembre], 206 páginas.

21) Un carnívoro cuchillo, Barcelona, Editorial Planeta, Colección «Narrativa», n. 102, 1988 [marzo], 174 páginas.

22) Nada en el domingo, Barcelona, Editorial Seix Barral, Colección «Biblioteca breve», 1988 [mayo], 140 páginas.

23) El día en que violé a Alma Mahler, Barcelona, Ediciones Destino, Colección «Áncora y delfín», n.ำ 621, 1988 [junio], 177 páginas.

24) El fulgor de África, Barcelona, Editorial Seix Barral, Colección «Biblioteca breve», 1989 [marzo], 188 páginas.

25) Y Tierno Galván ascendió a los cielos, Barcelona, Editorial Seix Barral, Colección «Biblioteca breve», 1990, 166 páginas.

26) Leyenda del César Visionario, Barcelona, Editorial Seix Barral, Colección «Biblioteca breve», 1991 [febrero], 190 páginas.

27) Memorias borbónicas, Barcelona, Editorial Planeta, Colección «Autores españoles e hispanoamericanos», 1992 [octubre], 227 páginas.

28) Madrid 1940. Memorias de un joven fascista, Barcelona, Editorial Planeta, Colección "Autores españoles e hispanoamericanos», 1993 [octubre], 246 páginas.

29) Las señoritas de Aviñón, Barcelona, Editorial Planeta, Colección «Autores españoles e hispanoamericanos», 1995 [enero], 236 páginas.

30) Madrid 650, Barcelona, Editorial Planeta, Colección «Autores españoles e hispanoamericanos», 1995 [noviembre], 253 páginas.

31) Capital del dolor, Barcelona, Editorial Planeta, Colección «Autores españoles e hispanoamericanos», 1996 [mayo], 234 páginas.

32) La forja de un ladrón, Barcelona, Editorial Planeta, Colección «Autores españoles e hispanoamericanos», 1997 [octubre], 246 páginas.

33) El socialista sentimental, Barcelona, Editorial Planeta, Colección «Autores españoles e iberoamericanos», 2000 [febrero], 195 páginas.

34) La rebelión de los delfines (La novela del 2000) [obra colectiva de 17 autores], Madrid, Munditeractivos y Editorial Espasa Calpe, 2001 [mayo], 221 páginas. Prólogo de Santos Sanz Villanueva. Francisco Umbral es el autor del primer capítulo.

35) Los metales nocturnos, Barcelona, Editorial Planeta, Colección «Autores españoles e iberoamericanos», 2003 [octubre], 200 páginas.

\section{Cuentos y narraciones breves}

36) Teléfono y ginebra inglesa, Madrid, separata de Cuadernos Hispanoamericanos, n. ${ }^{1}$ 157, 1963 [enero], 5 páginas.

37) Tamouré, de Francisco Umbral; El puño, de Alfonso Martínez-Mena Rodríguez, Alicante, Caja de Ahorros del Sudeste de España, Colección «Publicaciones de la Caja de Ahorros del Sudeste de España», n. 27, 1964, 25 páginas. Ilustraciones de Enrique Lledó y Manuel Baeza.

38) Tamouré (Relatos), Madrid, Editora Nacional, Colección «Prosistas españoles», 1965 [enero], 125 páginas. 
39) Días sin escuela, incluida en Tierras de León, León, Institución Fray Bernardino de Sahagún, V, n. ${ }^{\circ}$ 6, 1965 [octubre], pp. 87-102.

40) Una nueva luz y 29 premios más. El cuento en la literatura española actual [varios autores], Madrid, Confederación Española de Cajas de Ahorros, 1966, 264 páginas. Ilustraciones de Rafael Munoa y Marco.

41) La sonrisa que te llegaba y 24 cuentos más [varios autores], Madrid, Confederación Española de Cajas de Ahorros, 1968, XI + 276 páginas. Ilustraciones de Rafael Munoa.

42) Las vírgenes, Madrid, Editorial Azur, Colección «El surco derecho», n. 8, 1969, 94 páginas.

43) Últimos rumbos del cuento español [varios autores], Buenos Aires, Editorial Columba, Colección «Nuevos esquemas», n. 20, 1969 [junio], 306 páginas. Estudio preliminar de Eduardo Tijeras.

44) La mecedora, Madrid, separata de Revista de Occidente, n..99, 1971 [junio], 6 páginas.

45) Manifiesto español o una antología de narradores [varios autores], Barcelona, Ediciones Marte, Colección «Novela y documento», 1973 [marzo], 640 páginas. Edición de Antonio Beneyto.

46) Soy la soledad que toca el xilofón para pagar el alquiler, Madrid, Colección «Pliegos sueltos de La Estafeta», n.. 76, 1974 [diciembre], 8 páginas.

47) El día que perdí... aquello [varios autores], Madrid, Ediciones Sedmay, 1975 [febrero], 232 páginas. Edición de Jesús M.ª Amilibia y Yale (seudónimo de Felipe Navarro).

48) Diez narradores españoles [varios autores], Barcelona, Editorial Bruguera, 1977 [marzo], 217 páginas. Edición de Antonio Beneyto.

49) Teoría de Lola y otros cuentos, Barcelona, Ediciones Destino, Colección «Áncora y delfín», n.. 506, 1977 [mayo], 233 páginas.

50) Tatuaje y nueve relatos finalistas [varios autores], Madrid, Fundación de los Ferrocarriles Españoles, 1991 [junio], 101 páginas. Prólogo de Luis Vélez Riesco.

51) Aquel verano. 33 relatos firmados por las mejores plumas del panorama literario español [varios autores], Madrid, Editorial Espasa Calpe, 1996 [junio], 239 páginas.

52) 1960-1996. Premios Gabriel Miró [varios autores], Murcia, Caja de Ahorros del Mediterráneo, 1996 [noviembre], 319 páginas.

53) Aquel verano, aquel amor. 33 escritores confiesan un amor de verano [varios autores], Madrid, Editorial Espasa Calpe, Colección «Espasa selección», 1997 [mayo], 191 páginas. Prólogo de Juan Carlos Laviana.

54) El sueño de un verano [varios autores], Madrid, El Mundo y Editorial Espasa Calpe, 1998 [junio], 247 páginas. Prólogo de Gabriel Albiac.

55) Cien años de cuentos (1898-1998). Antología del cuento español en castellano [varios autores], Madrid, Ediciones Alfaguara, Colección «Extra Alfaguara», 1998 [julio], 575 páginas. Prólogo y selección de José M.․ㅗ Merino.

56) Cuentos de fútbol 2 [varios autores], Madrid, Ediciones Alfaguara, Colección «Extra Alfaguara», 1998 [octubre], 338 páginas. Prólogo y selección de Jorge Valdano.

57) Historias de amor y Viagra, Barcelona, Editorial Planeta, Colección «Autores españoles e iberoamericanos. Biblioteca Francisco Umbral», 1998 [noviembre], 239 páginas. 
58) El cuento literario en Castilla y León. I: Antología [varios autores], LeónValladolid, Edilesa-Junta de Castilla y León, Colección «Vuelapluma», n. ํ 4, 2000 [enero; el depósito legal del libro pertenece a 1999], 158 páginas. Edición de José Luis Puerto.

59) De Madrid... al cielo [varios autores], Barcelona, Muchnik Editores, 2000 [abril], 183 páginas. Edición de Rosa Regàs. Introducción de Francisco Ayala.

60) Cuentos de hijos y padres. Estampas de familia [varios autores], Madrid, Editorial Páginas de Espuma, «Narrativa breve», n. 5, 2001 [abril], 278 páginas. Prólogo de Diego Muñoz Valenzuela. Selección de Viviana Paletta y Javier Sáez de Ibarra.

\section{Poesía}

61) Crímenes y baladas (Antología), Cuenca, Editorial Olcades, Colección "César», n.ำ1, 1981 [agosto], 143 páginas. Ilustración de Julián Grau Santos.

62) Soneto, Málaga, Imprenta Dardo, Colección «El camaleón», n. 5, 1987, 4 páginas. Ilustración de Ma José Vargas-Machuca.

63) Obra poética (1981-2001), Barcelona, Editorial Seix Barral, Colección «Los tres mundos/Poesía», 2009 [mayo], 299 páginas. Edición de Miguel García-Posada.

\section{Artículos}

64) Amar en Madrid, Barcelona, Editorial Planeta, Colección «Biblioteca universal Planeta/Mosaico», n.o 1, 1972 [enero], 220 páginas.

65) Spleen de Madrid, Madrid, Organización Sala Editorial, 1972 [diciembre; el depósito legal del libro pertenece a 1973], 255 páginas.

66) Diario de un snob, Barcelona, Ediciones Destino, Colección "Áncora y delfín», n.ำ 427, 1973 [marzo], 284 páginas.

67) Periodismo político en la España actual [varios autores], Madrid, Fundación Continental-Ediciones Castilla, 1973 [octubre], 693 páginas. Edición de Gabriel Elorriaga. 68) Museo nacional del mal gusto, Esplugues de Llobregat (Barcelona), Plaza \& Janés Editores, Colección «Testigos de España», n. 1, 1974 [febrero], 187 páginas.

69) Crónicas antiparlamentarias, Madrid, Ediciones Júcar, Colección «La vela latina/ Crónica», n.o 9, 1974 [marzo], 237 páginas.

70) Diario de un español cansado, Barcelona, Ediciones Destino, Colección «Áncora y delfín», n.․ 473, 1975 [junio], 286 páginas.

71) Suspiros de España, Madrid, Ediciones Felmar, Colección «Punto crítico/Serie B», n..$^{\text {4 }} 1975$ [noviembre], 343 páginas.

72) La guapa gente de derechas, Barcelona, Luis de Caralt Editor, Colección «Biblioteca universal Caralt/Testimonio», n.․ 32, 1975 [noviembre], 226 páginas.

73) Papeles sobre la «nueva novela» española [varios autores], Barañáin (Navarra), Ediciones Universidad de Navarra, Colección «Temas NT», 1975 [diciembre], 203 páginas. Edición de Manuel García Viñó.

74) Cabecitas locas, boquitas pintadas y corazones solitarios, Madrid, Ediciones 99, 1975 [diciembre], 152 páginas.

75) España cañí, Esplugues de Llobregat (Barcelona), Plaza \& Janés Editores, Colección «Testigos de España», n. 13, 1975 [diciembre], 190 páginas.

76) Crónicas post-franquistas, Madrid, A. Q. Ediciones, 1976 [marzo], 290 páginas.

77) Mis mujeres, Barcelona, Editorial Planeta, Colección «Textos», n.. 13, 1976 [abril], 329 páginas. 
78) Los políticos, Madrid, Ediciones Sedmay, 1976 [mayo], 190 páginas.

79) Caperucita y los lobos [en colaboración con Manuel Vicent y Carlos Luis Álvarez], Madrid, A. Q. Ediciones, Colección «Humor actualidad», n. 2, 1976 [junio], 220 páginas. Dibujos de Ramón.

80) España de parte a parte [en colaboración con Manuel Vicent, Carlos Luis Álvarez y Antonio Burgos], Madrid, A. Q. Ediciones, Colección «Humor actualidad», n. 3, 1976 [noviembre], 170 páginas.

81) Iba yo a comprar el pan..., Madrid, Ediciones Sedmay, 1976 [diciembre], 215 páginas.

82) Las jais, Madrid, Ediciones Sedmay, 1977 [enero], 215 páginas.

83) Diario de un snob/2, Barcelona, Editorial Bruguera, Colección «Bruguera libro amigo", n.․ 1502/594, 1978 [agosto], 408 páginas.

84) Diario de un escritor burgués, Barcelona, Ediciones Destino, Colección «Áncora y delfín», n. 534, 1979 [abril], 291 páginas.

85) Spleen, cuaderno madrileño, Madrid, Ediciones de Arte y Bibliofilia-Galería Biosca, 1981 [marzo], 28 páginas + 12 hojas. Aguafuertes de Amalia Avia.

86) Los ángeles custodios, Barcelona, Ediciones Destino, Colección «Áncora y delfín», ก.․5 553, 1981 [mayo], 263 páginas.

87) Así fue el 18 de julio [varios autores], Madrid, monográfico de Tiempo de Historia, n.. 80-81, 1981, 226 páginas.

88) Spleen de Madrid/2, Barcelona, Ediciones Destino, Colección «Áncora y delfín», n.․ 564, 1982 [abril], 315 páginas.

89) España como invento, Madrid, Ediciones Libertarias-Prodhufi, Colección «Pluma rota/Ensayo», n.. 6, 1984 [septiembre], 253 páginas.

90) Memorias de un hijo del siglo, Madrid, Ediciones El País, Colección «En El País», n. ${ }^{\circ}$ 15, 1987 [marzo], 220 páginas.

91) Cinco años que cambiaron el mundo: 1989-1994 [varios autores], Madrid, El Mundo, 1994 [octubre], 256 páginas. Edición de Juan Carlos Laviana.

92) Mis placeres y mis días, Madrid, Editorial Espasa Calpe, Colección «Textos escogidos», 1994 [octubre], 286 páginas.

93) 70 columnistas de la prensa española [varios autores], Barañaín (Navarra), Ediciones Universidad de Navarra, Colección «Manuales Ciencias de la Información», 1995 [abril], 116 páginas. Estudio introductorio de Fernando López Pan.

94) Contra el poder [varios autores], Madrid, Ediciones Temas de Hoy, Colección «Grandes temas», n. 53, 1996 [enero], 214 páginas.

95) Artículos periodísticos (1900-1998) [varios autores], Madrid, Editorial Castalia, Colección «Castalia didáctica», n. 50, 1999 [octubre], 328 páginas. Edición de Francisco Gutiérrez Carbajo.

96) XXV Artículos ganadores y un epílogo de César González-Ruano [varios autores], Madrid, Fundación Cultural Mapfre Vida, 2000, 221 páginas.

97) Un siglo en 100 artículos [varios autores], Madrid, La Esfera de los Libros, Colección «La Esfera literaria», 2002 [febrero], 526 páginas. Edición de Justino Sinova.

98) La república bananera USA, Madrid, Ediciones Irreverentes, Colección «Rara avis», n. $.1,2002$ [septiembre], 92 páginas.

99) Articulismo español contemporáneo. Una antología [varios autores], Madrid, Mare Nostrum Comunicación, Colección «Clásicos Marenostrum», n. ${ }^{\circ}$ 6, 2004, 301 páginas. Introducción y selección de Pedro de Miguel. 
100) Artículos literarios en la prensa (1975-2005) [varios autores], Madrid, Ediciones Cátedra, Colección «Letras hispánicas», n.5 599, 2007 [enero], 293 páginas. Edición de Francisco Gutiérrez Carbajo y José Luis Martín Nogales.

\section{Ensayos, biografías, ponencias y reflexiones literarias}

101) José García Nieto. Semblanza directa y esquema biográfico, Madrid, separata de Revista Punta Europa, n. . 83, 1963 [marzo], 12 páginas.

102) Larra. Anatomía de un dandy, Madrid, Ediciones Alfaguara, Colección «Los ojos abiertos», n.. 2, 1965 [mayo], 279 páginas.

103) Prosa novelesca actual [varios autores], Santander, Universidad Internacional Menéndez Pelayo, 1968, 185 páginas. Edición de Francisco Ynduráin.

104) Lorca, poeta maldito, Madrid, Editorial Biblioteca Nueva, 1968 [septiembre], 272 páginas.

105) Valle-Inclán, Madrid, Unión Editorial, Colección «Grandes escritores contemporáneos», n.. 2, 1968 [noviembre], 166 páginas.

106) Biografía completa de George Gordon, lord Byron, Madrid, Ibérico Europea de Ediciones, Colección «Los protagonistas de la historia», 1969, 32 páginas.

107) Prosa novelesca actual (Segunda reunión, agosto de 1968) [varios autores], Santander, Universidad Internacional Menéndez Pelayo, 1969, 290 páginas. Edición de Francisco Ynduráin.

108) Miguel Delibes, Madrid, Ediciones y Publicaciones Españolas, Colección «Grandes escritores contemporáneos», n.. 35, 1970 [enero], 186 páginas.

109) Lola Flores (Sociología de la petenera), Barcelona, Editorial Dopesa, Colección «Nuestros contemporáneos», n..$^{3}$ 3, 1971 [enero], 98 páginas.

110) Encuentros con don Pío. Homenaje a Baroja [varios autores], Madrid, Al-Borak S. A. de Ediciones, 1972 [enero], 219 páginas.

111) La España ausente [varios autores], Madrid, Ediciones 99, 1973 [marzo], 200 páginas.

112) Las españolas, Barcelona, Editorial Planeta, Colección «Espejo de España/Serie Los españoles», n.. 5, 1974 [junio], 350 páginas.

113) Tratado de perversiones, Barcelona, Librería Editorial Argos, 1977 [enero], 220 páginas.

114) Ramón y las vanguardias, Madrid, Editorial Espasa Calpe, Colección «Selecciones Austral/Ensayo», n. 50, 1978 [diciembre], 246 páginas. Prólogo de Gonzalo Torrente Ballester.

115) Homenaje a Antonio Machado en el XL Aniversario de su muerte, mayo de 1979 [varios autores], Madrid, Universidad Complutense, 1979, $48+90$ páginas.

116) El libro como ocasión, Madrid, Asociación de Libreros de Lance de Madrid, 1980, 3 páginas.

117) Rodolfo Walsh secuestrado por la Junta Militar argentina [varios autores], Madrid, Ediciones del Rescate, Colección «Serie de los trabajadores de la cultura represaliados en Argentina», n. 2, 1981 [marzo],154 páginas.

118) Homenaje a Gonzalo Torrente Ballester [varios autores], Salamanca, Caja de Ahorros y Monte de Piedad de Salamanca, Colección «Biblioteca académica», n. ${ }^{\circ}$ 1, 1981 [junio], XVI + 681 páginas. 
119) Neruda joven. Cartas y poemas de Pablo Neruda a Albertina Rosa Azócar [varios autores], Madrid, Edilán, Banco Exterior de España, 1983 [septiembre], tres tomos. Prólogo de Vicente Aleixandre. Introducción de Juan Ignacio Poveda.

120) Fábula del falo, Barcelona, Editorial Kairós, 1985 [abril], 146 páginas.

121) El fetichismo, Madrid, El Observatorio Ediciones, Colección «Las buenas lecturas», n.ำ 7, 1986 [febrero], 164 páginas.

122) La escritura perpetua, Madrid, Fundación Cultural Mapfre Vida, 1989 [junio], 144 páginas.

123) Homenaje al profesor Antonio Vilanova. Volumen I [varios autores], Barcelona, Departamento de Filología Española de la Universidad de Barcelona-Promociones y Publicaciones Universitarias, 1989 [agosto], 866 páginas. Edición de Marta Cristina Carbonell.

124) Exposición antológica Francisco Nieva: teatro Albéniz, marzo-mayo 1990 [varios autores], Madrid, Centro de Estudios y Actividades Culturales, 1990 [abril], 125 páginas. Edición de Andrés Peláez y Fernanda Andura.

125) El socialfelipismo. La democracia detenida, Barcelona, Ediciones B, Colección «Reporter», n. 68, 1991 [noviembre], 293 páginas.

126) Del 98 a don Juan Carlos, Barcelona, Editorial Planeta, Colección «Espejo de España/Serie Los españoles», n. ${ }^{\circ}$ 151, 1992 [marzo], 384 páginas.

127) El autor y su obra: Miguel Delibes [varios autores], Madrid, Editorial Actas, Colección «Actas de El Escorial», n.ํ5, 1993 [diciembre], 193 páginas. Edición de José Jiménez Lozano, Ramón García-Domínguez y Gonzalo Santonja.

128) Miguel Delibes, premio Letras Españolas 1991 [varios autores], Madrid, Dirección General del Libro y Bibliotecas del Ministerio de Cultura, Centro de las Letras Españolas, 1993, 275 páginas.

129) Las palabras de la tribu (De Rubén Darío a Cela), Barcelona, Editorial Planeta, Colección «Documento», 1994 [febrero], 358 páginas.

130) La derechona, Barcelona, Editorial Planeta, Colección «Documento», 1997 [febrero], 262 páginas.

131) Escritores ante el espejo. Estudio de la creatividad literaria [varios autores], Barcelona, Editorial Lumen, Colección «Palabra crítica», n. 24, 1997, 399 páginas. Edición de Anthony Percival.

132) Cela y el mal amor, Iria Flavia (La Coruña), separata de El Extramundi y Los Papeles de Iria Flavia, n.ํIX, 1997, 10 páginas.

133) Retratos literarios. Escritores españoles del siglo $X X$ evocados por sus contemporáneos [varios autores], Madrid, Editorial Espasa Calpe, Colección «Espasa selección», 1997 [octubre], 358 páginas. Edición de Laura Freixas.

134) Valle-Inclán. Los botines blancos de piqué, Barcelona, Editorial Planeta, Colección «La España plural», 1998 [enero], 275 + 40 páginas.

135) Madrid, tribu urbana. Del socialismo a don Froilán, Barcelona, Editorial Planeta, Colección «La España plural», 2000 [octubre], 263 páginas.

136) Los alucinados. Personajes, escritores, monstruos. Una historia diferente de la literatura, Madrid, La Esfera de los Libros, 2001 [septiembre], 196 páginas. Prólogo de José Antonio Marina.

137) Los escritores de Madrid vistos por Umbral y Alfonso, Madrid, Universidad de Alcalá de Henares, 2001, 123 páginas.

138) Cela, un cadáver exquisito. Vida y obra, Barcelona, Editorial Planeta, 2002 [abril], 224 páginas. 
139) ¿Y cómo eran las ligas de madame Bovary?, Barcelona, Ediciones Destino, Colección «Imago mundi», n.. 23, 2003 [enero], 210 páginas.

140) Miguel Delibes. Homenaje académico y literario [varios autores], Valladolid, Universidad de Valladolid-Junta de Castilla y León, 2003, 214 páginas. Edición de M.ª Pilar Celma.

141) José Hierro (1922-2002). La torre de los sueños [varios autores], Santander, Museo de Bellas Artes de Santander, Consejería de Cultura, Turismo y Deporte del Gobierno de Cantabria, 2004 [diciembre], 637 páginas.

142) Amado siglo XX, Barcelona, Editorial Planeta, Colección «Autores españoles e iberoamericanos», 2007 [febrero], 295 páginas.

143) La poesía de Diego Jesús Jiménez [varios autores], Cuenca, Servicio de Publicaciones de la Universidad de Castilla-La Mancha, Colección «Humanidades», n.o 91, 2007 [marzo], 676 páginas. Edición de J. M. Molina y M. Muelas.

\section{Memorias, diarios y cartas}

144) Memorias de un niño de derechas, Barcelona, Ediciones Destino, Colección «Áncora y delfín», n. 392, 1972 [abril], 178 páginas.

145) Carta abierta a una chica "progre», Madrid, Ediciones 99, Colección «Carta abierta», 1973 [abril], 124 páginas.

146) Mis paraísos artificiales, Barcelona, Librería Editorial Argos, 1976 [marzo], 194 páginas.

147) Las cartas, Madrid, Ediciones Sedmay, 1976 [diciembre], 148 páginas.

148) La noche que llegué al Café Gijón, Barcelona, Ediciones Destino, Colección «Áncora y delfín», n. ํ524, 1977 [diciembre], 262 páginas.

149) Trilogía de Madrid (Memorias), Barcelona, Editorial Planeta, Colección «Narrativa», n. $.71,1984$ [febrero], 337 páginas.

150) Crónica de esa guapa gente. Memorias de la jet, Barcelona, Editorial Planeta, Colección «Documento», n.. 298, 1991 [octubre], 323 páginas.

151) Memorias eróticas. Los cuerpos gloriosos, Madrid, Ediciones Temas de Hoy, Colección «Biblioteca erótica», n.․ 17, 1992 [febrero], 239 páginas.

152) La década roja, Barcelona, Editorial Planeta, Colección «Documento», n. $³ 32$, 1993 [marzo], 379 páginas.

153) Los cuerpos gloriosos. Memorias y semblanzas, Barcelona, Editorial Planeta, Colección «Documento», 1996 [enero], $298+16$ páginas.

154) Los cuadernos de Luis Vives, Barcelona, Editorial Planeta, Colección «La España plural», 1996 [septiembre], $188+8$ páginas.

155) Diario político y sentimental, Barcelona, Editorial Planeta, Colección «Autores españoles e iberoamericanos. Biblioteca Francisco Umbral», 1999 [febrero], 443 páginas. 156) Un ser de lejanías, Barcelona, Editorial Planeta, Colección «Autores españoles e iberoamericanos», 2001 [abril], 222 páginas.

157) Días felices en Argüelles, Barcelona, Editorial Planeta, Colección «Autores españoles e iberoamericanos», 2005 [marzo], 227 páginas.

158) Carta a mi mujer, Barcelona, Editorial Planeta, Colección «Autores españoles e iberoamericanos», 2008 [febrero], 173 páginas. Prólogo de Pere Gimferrer. 


\section{Diccionarios, guías y libros de entrevistas del autor}

159) Diccionario para pobres, Madrid, Ediciones Sedmay, 1977 [mayo], 198 páginas. Ilustraciones de Alfredo González Sánchez. Prólogo de Luis Otero.

160) El libro de Madrid [varios autores], Oviedo, Ediciones Naranco, 1977 [noviembre], 484 páginas.

161) Teoría de Madrid, Madrid, Editorial Espasa Calpe, 1981 [el depósito legal es de 1980], 262 páginas. Ilustraciones de Alfredo González.

162) Diccionario cheli, Barcelona, Ediciones Grijalbo, Colección «Narrativa 80», 1983 [marzo], 255 páginas.

163) Mis queridos monstruos, Madrid, Editorial Prisa, Colección «En El País», n.ㄹ 2, 1985 [marzo], 265 páginas. Dibujos de José Luis Verdes. Prólogo de Juan Luis Cebrián.

164) Guía de pecadores/as (Todos los que están), Barcelona, Editorial Anagrama, Colección «Contraseñas», n. ${ }^{\circ}$ 77, 1986 [marzo], 215 páginas.

165) Valladolid, vivencias y fotografías [varios autores], Valladolid, Grupo Pinciano, 1986 [noviembre], 235 páginas.

166) Guía de la posmodernidad. Crónicas, personajes e itinerarios madrileños, Madrid, Ediciones Temas de Hoy, Colección «El papagayo», n.ำ 2, 1987 [septiembre], 142 páginas. Ilustraciones de Ceesepe.

167) Guía irracional de España, Madrid, Arnao Ediciones, Colección «Verbigracia», n. ${ }^{4}$ 4, 1989 [mayo], 199 páginas.

168) Todo Madrid [varios autores], Madrid, Arnao Ediciones, 1989 [junio], 355 páginas.

169) Diccionario de literatura. España 1941-1995: De la posguerra a la posmodernidad, Barcelona, Editorial Planeta, Colección «Diccionarios de autor», 1995 [septiembre], 277 páginas.

170) Gran Bilbao, 1998 [varios autores], Bilbao, Diputación Foral de Bizkaia, 1998, 206 páginas. Aguafuerte de M. Puri Herrero.

171) Madrid XXI, Barcelona, Lunwerg Editores y Repsol YPF, 2000 [diciembre], 132 páginas. Fotografías de Alberto Schommer.

172) Crónica de las tabernas leonesas, León, El Búho Viajero, Colección «Biblioteca leonesa de interesantes, agotados y raros», n. 11, 2004 [marzo], $31+38$ páginas. Prólogo de Fulgencio Fernández.

\section{Catálogos y escritos de arte}

173) Llorens Poy [en colaboración con Carlos Luis Álvarez, Manuel Vicent y Josep Meliá], Madrid, Ediciones Rayuela, Colección «Maniluvios», n.ำ 7, 1977 [enero], 109 páginas.

174) Óscar Estruga: Esculturas y dibujos, Madrid, Galería Biosca, 1981 [abril], 28 páginas.

175) Sorolla, Solana [varios autores], Liège, Salle Saint Georges, 1985 [octubre], 182 páginas.

176) Yraola [varios autores], Segovia, Caja de Ahorros y Monte de Piedad de Segovia, Colección «Torreón de Lozoya», 1988, 140 páginas.

177) Mejía Lequerica: Exposición retrospectiva 1992-1995 [varios autores], Madrid, Área de Educación, Juventud y Deportes del Ayuntamiento de Madrid, 1995 [marzo], 205 páginas.

178) Paloma Monrós: Escenas madrileñas [varios autores], Madrid, 1996. 
179) Carlos Killian: Mucho más que humor [varios autores], Madrid, Junta Municipal de Moncloa-Aravaca del Ayuntamiento de Madrid, 2002, 59 páginas.

180) Grau Santos: Pinturas, Madrid, Galería Juan Gris, 2002 [abril], 24 páginas.

181) Ramón Masats. La memoria construida [varios autores], Madrid, Dirección General de Archivos, Museos y Bibliotecas, 2002 [diciembre], 174 páginas.

182) Sofía Morales. Sala de exposiciones de la Fundación Cajamurcia en Madrid, del 7 de octubre al 7 de noviembre de 2005 [varios autores], Murcia, Murcia Cultural, 2005 [junio], 156 páginas.

183) Agustín Úbeda: Realidades de la mente [varios autores], Gijón, Sala de Arte Van Dyck, 2007 [marzo], 24 páginas.

184) Picasso, pinxit y dixit [varios autores], La Coruña, Editorial Camiño do Faro, Colección «Los papeles de Salamanca», 2008 [agosto], 144 páginas. Coordinación de Lucindo-Javier Membiela.

185) Alfredo debuxa o camiño [varios autores], La Coruña, Xunta de Galicia, 2009, 366 páginas.

\section{Prólogos, epílogos e introducciones}

186) La hoja roja, de Miguel Delibes, Barcelona, Salvat Editores, Colección «Biblioteca básica Salvat de libros RTV», n.ำ17, 1969, 189 páginas. Prólogo de Francisco Umbral.

187) El laurel y los días, de Manuel Ríos Ruiz, Barcelona, Ediciones Picazo, Colección «El juglar y la luna», 1971 [enero], 114 páginas. Prólogo de Francisco Umbral.

188) Mujeres, de Luis Marañón, Madrid, Editorial Prensa Española, 1972 [enero], 137 páginas. Prefacio de Francisco Umbral.

189) 100 años de canción y music hall, de Manuel Vázquez Montalbán, Barcelona, Difusora Internacional, 1974 [abril], 476 páginas. Prólogo de Francisco Umbral.

190) Estrellas y «stars», de Antonio D. Olano, Barcelona, Editorial Dopesa, Colección «Castas de españoles», n. 3, 1974 [mayo], 488 páginas. Prólogo de Francisco Umbral.

191) La frente contra el muro y Madrid, amor, tristeza, de Javier Villán, Cáceres, La Encina Editorial, Colección «La casa encendida», n.ำ 2, 1975 [febrero], 51 páginas. Prólogo de Francisco Umbral.

192) El jardín perfumado, de Umar b. Muhammad Al-Nafzawi, Madrid, Editorial Felmar, Colección «La fontana literaria», n.ำ 29, 1975 [abril], 294 páginas. Prólogo de sir Richard Burton. Epílogo de Francisco Umbral. Traducción de José González Vallarino.

193) Yo fui chica de alterne, de Carmen Rigalt, Madrid, Ediciones Sedmay, 1976 [enero], 237 páginas. Prólogo de Francisco Umbral.

194) Cosas mías, de José Luis Coll, Barcelona, Editorial Planeta, Colección «Fábula», n. 1,1976 [abril], 258 páginas. Prólogo de Francisco Umbral.

195) Animales sagrados, de Luis Otero, Barcelona, Editorial Personas, 1976 [mayo], 382 páginas. Prólogo de Francisco Umbral.

196) Tamaño natural, de Luis García Berlanga y Rafael Azcona, Madrid, Ediciones Sedmay, Colección «Séptimo arte», n. 6, 1976 [junio], 196 páginas. Prólogo de Francisco Umbral.

197) La santa bohemia: Alejandro Sawa, Manuel Paso, Pedro Barrantes, Pedro Luis de Gálvez, Alfonso Vidal y Planas..., de José Fernando Dicenta, Madrid, Ediciones del Centro, Colección «Literatura», n. ${ }^{\circ}$ 42, 1976 [octubre], 207 páginas. Introducción de Francisco Umbral. 
198) Figuras de la fiesta nacional, de Francisco Cerecedo, Madrid, Ediciones Sedmay, 1977 [octubre], 118 páginas. Prólogo de Francisco Umbral.

199) Don Juan (hoy). Innovación y tradición en el teatro y el ensayo del siglo XX en España, de Gladys Crescioni Neggers. Madrid, Ediciones Turner, 1978 [enero; el depósito legal del libro pertenece a 1977], 150 páginas. Prólogo de Francisco Umbral. Epílogo de Ernesto Giménez Caballero.

200) Historia de una tertulia, de Antonio Díaz-Cañabate, Madrid, Editorial Espasa Calpe, Colección «Selecciones Austral», n.ํ 38, 1978 [mayo], 284 páginas. Prólogo de Francisco Umbral.

201) Larra. Autopsia de un suicidio (Ensayo poético), de Daniel Blanquer Marset, Alcoy, Imprenta Hispana Alcoyana, 1978 [junio], 46 páginas. Prólogo de Francisco Umbral. Ilustraciones de Francisco Gisbert e Ismael Belda.

202) Antología fugaz, de Mariano José de Larra, Madrid, Alianza Editorial, Colección «El libro de bolsillo», n.. 737, 1979, 222 páginas. Prólogo y selección de Francisco Umbral.

203) Se llama Tomelloso... y así lo ven sus pintores y escritores [varios autores], Madrid, Org. Gráf. Sierra de Monchique, 1979 [mayo], 205 páginas. Prólogo de Francisco Umbral. Dibujo de Antonio López Torres.

204) El Pobrecito Hablador (Revista satírica de costumbres, etc., etc.), de Mariano José de Larra, Madrid, Editorial Espasa Calpe, 1979 [noviembre], XII + 280 páginas. Prólogo de Francisco Umbral.

205) El arte de amar, de Ovidio; El asno de oro, de Apuleyo, Barcelona, Círculo de Lectores, Colección "Grandes clásicos universales», 1980, 412 páginas. Ensayo preliminar de Francisco Umbral. Traducción del latín de Lisardo Rubio Fernández.

206) El último austro-húngaro: Conversaciones con Berlanga, de Juan Hernández Les y Manuel Hidalgo, Barcelona, Editorial Anagrama, Colección «Cinemateca Anagrama», n. 17, 1981 [febrero], 157 páginas. Prólogo de Francisco Umbral.

207) Raíces del edén, de Rafael Muñoa Gibello, Madrid, Gráficas Luna, 1981, 126 páginas. Prólogo de Francisco Umbral.

208) De una niña de provincias que se vino a vivir en un Chagall, de Blanca Andreu, Madrid, Ediciones Hiperión, Colección «Poesía Hiperión», n.ํ50, 1984, 64 páginas. Prólogo de Francisco Umbral.

209) Mazurca para dos muertos, de Camilo José Cela, Barcelona, Círculo de Lectores, Colección «Maestros de la narrativa hispánica», 1984, 244 páginas. Introducción de Francisco Umbral.

210) El viaje a ninguna parte, de Fernando Fernán-Gómez, Madrid, Editorial Debate, Colección «Debate literatura», n. 32, 1987, 268 páginas. Prólogo de Francisco Umbral.

211) Memorias, de María Asquerino, Esplugues de Llobregat (Barcelona), Plaza \& Janés Editores, Colección «Biografías y memorias», 1987 [marzo], 311 + 16 páginas. Prólogo de Francisco Umbral.

212) Yerma; Mariana Pineda, de Federico García Lorca, Barcelona, Ediciones B, Colección «Libro amigo/Narrativa», n. 30, 1987 [octubre], 233 páginas. Prólogo de Francisco Umbral.

213) Bodas de sangre; Amor de don Perlimplín con Belisa en su jardín, de Federico García Lorca, Barcelona, Ediciones B, Colección «Libro amigo/Narrativa», n.. 31, 1987 [octubre], 171 páginas. Prólogo de Francisco Umbral. 
214) La casa de Bernarda Alba; Doña Rosita la soltera o El lenguaje de las flores, de Federico García Lorca, Barcelona, Ediciones B, Colección «Libro amigo/Narrativa», n. ${ }^{-}$32, 1987 [octubre], 222 páginas. Prólogo de Francisco Umbral.

215) Hijos de un largo viento, de Ana María Badell, Gijón, Fundación Dolores Medio, 1988 [abril], 176 páginas. Prólogo de Francisco Umbral. Epílogo de Pedro Laín Entralgo.

216) Operación Niebla, de Francisco Javier Aguirre, Logroño, Consejería de Educación, Cultura y Deportes del Gobierno de La Rioja, Colección «Chapiteles», n.․2, 1991 [febrero], 110 páginas. Proemio de Francisco Umbral.

217) Isabel Preysler, reina de corazones, de Paloma Barrientos, Barcelona, Ediciones B, Colección «Primer plano», n.o 4, 1991 [marzo], 215 + 52 páginas. Prólogo de Francisco Umbral.

218) Francisco Umbral, de Ángel-Antonio Herrera, Madrid, Grupo Libro 88, Colección «¿Yo soy así?», n. 5, 1991 [diciembre], 157 + 16 páginas. Epílogo de Francisco Umbral.

219) La romana, de Alberto Moravia, Madrid, Editorial Espasa Calpe, 1992 [noviembre], 426 páginas. Prólogo de Francisco Umbral. Traducción de Francisco Ayala.

220) La ex siempre llama dos veces... (...o las consecuencias de tener un marido de segunda mano), de Beatriz Pérez-Aranda y Mari Pau Domínguez, Barcelona, Ediciones B, Colección «Dolce vita», 1993, 249 páginas. Prólogos de Francisco Umbral y Andrés Aberasturi.

221) La venganza de don Mendo, de Pedro Muñoz Seca, Barcelona, Círculo de Lectores-Galaxia Gutenberg, 1994 [febrero], 217 páginas. Prólogos de Francisco Umbral y Alfonso Ussía. Ilustraciones de Antonio Mingote.

222) Artículos, de Mariano José de Larra, Barcelona, Círculo de Lectores, 1994 [noviembre], 343 páginas. Prólogo de Francisco Umbral.

223) El tercer hombre: P. J., la pesadilla de F. G., de Esther Esteban, Madrid, Editorial Espasa Calpe, Colección «Espasa hoy», 1995, 321 páginas. Prólogo de Francisco Umbral.

224) Diccionario de términos taurinos, de Pedro Beltrán Rentero, Madrid, Aldebarán Ediciones, Colección «Dido diccionarios», 1996 [abril], 236 páginas. Prólogo de Francisco Umbral.

225) Cuentos cuentos, de Jorge Ferrer-Vidal, Alfonso Martínez-Mena y Meliano Peraile, Madrid, Ediciones Libertarias-Prodhufi, 1996 [septiembre], 215 páginas. Prólogo de Florencio Martínez Ruiz. Epílogo de Francisco Umbral.

226) Conciencias naturales, de Antonio Mingote, Madrid, Editorial Afanias, Colección «Sociología animada», n.ำ 2, 1996 [noviembre], 128 páginas. Prólogo de Francisco Umbral.

227) Escritores contra el racismo (Relatos) [varios autores], Madrid, Talasa Ediciones, Colección «Talasa literatura», n. 6, 1998 [junio], 151 páginas. Prólogo de Francisco Umbral.

228) Sale el sol y ocho cuentos más, de Jorge Cela Trulock, Madrid, Calambur Editorial, Colección «Calambur», n. 10, 1999 [abril], 91 páginas. Prólogo de Francisco Umbral.

229) El ingenioso hidalgo don Quijote de la Mancha, de Miguel de Cervantes Saavedra, Madrid, Edaf, 1999 [abril], 764 páginas. Ilustraciones de Enrique Herreros. Prólogo de Francisco Umbral.

230) El ingenioso hidalgo don Quijote de la Mancha. Parte I, de Miguel de Cervantes Saavedra, Madrid, Unidad Editorial, Colección «Millenium. Las 100 joyas del milenio», n. ํ 1, 1999, 430 páginas. Prólogo de Francisco Umbral. Edición de Martín Alonso. 
231) La segunda vida de Anita Ozores, de Ramón Tamames, Madrid, Sial Ediciones, Colección «Sial narrativa», n. ${ }^{\circ}$ 4, 2000, 491 páginas. Prólogo de Francisco Umbral.

232) Los objetos del siglo, Madrid, Ediciones Condé Nast, 2000. Dibujos de Eduardo Úrculo. Introducción de Francisco Umbral.

233) Vísperas, festividad y octava de San Camilo del año 1936 en Madrid, de Camilo José Cela, Barcelona, Bibliotex, Colección «Millenium. Las mejores novelas en castellano del siglo XX», n.. 57, 2001 [junio], 319 páginas. Prólogo de Francisco Umbral.

234) ¡Va por ellas! Las mujeres de los toreros. Una tauromaquia sentimental, de M. Ángeles Grajal, Barcelona, Editorial Planeta, 2002, 341 páginas. Prólogo de Francisco Umbral.

235) Sexus, 1, de Henry Miller, Barcelona, MDS Books, Mediasat, Colección «Biblioteca El Mundo. Las mejores novelas de la literatura universal contemporánea», n. ${ }^{2}$ 39, 2002 [diciembre], 270 páginas. Prólogo de Francisco Umbral. Traducción de Carlos Manzano.

236) Umbral. Las verdades de un mentiroso ilustre, de Eduardo Martínez Rico, Gijón, Llibros del Pexe, n. 41, 2003 [septiembre], 356 páginas. Epílogo de Francisco Umbral.

237) Seis poemas galegos, de Federico García Lorca, La Coruña, Editorial Camiño do Faro, 2004 [junio], 41 páginas. Introducción de Francisco Umbral. Ilustraciones de Carlos Fernández y Sally Cutting.

238) Diario íntimo (1951-1965), de César González-Ruano, Madrid, Visor Libros, Colección «Letras madrileñas contemporáneas», n.ํ12, 2004, 1161 páginas. Prólogo de Francisco Umbral.

239) Mis 100 mejores cartas del director. 25 años de la vida de España (1980-2005), de Pedro J. Ramírez, Madrid, La Esfera de los Libros, 2005 [mayo], 686 páginas. Prólogo de Francisco Umbral. Ilustraciones de Ricardo, Gallego \& Rey y Ulises.

240) Cinco litros de sangre (Memorias de un cirujano y empresario de la medicina privada), de Juan Abarca Campal, Boadilla del Monte (Madrid), J de J Editores, 2007 [mayo], 371 páginas. Prólogo de Francisco Umbral.

\section{Obra miscelánea}

241) España. Perspectiva 1973 [varios autores], Madrid, Guadiana de Ediciones, 1973 [marzo], 301 páginas.

242) Charlie Rivel [varios autores], Cubelles (Barcelona), Ajuntament de Cubelles, 1976 [agosto], 156 páginas. Ilustraciones de Soler-Jové.

243) Antología artística y literaria de la Lotería Nacional (1958-1977) [varios autores], Madrid, Fábrica Nacional de Moneda y Timbre, 1978, 326 páginas. Prólogo de Francisco López Cirugeda. Epílogo de Antonio Gómez Gutiérrez.

244) Cómo ríen los españoles [varios autores], Esplugues de Llobregat (Barcelona), Plaza \& Janés Editores, Colección «Rotativa», n.ำ220, 1979 [mayo], 183 páginas. Selección de León-Ignacio.

245) El metro de Madrid. Gente, colores, gestos [varios autores], Madrid, Compañía Metropolitana, 1985 [abril], 186 páginas.

246) La braga, Madrid, La Nueva Ilustración, 1990, 3 páginas. Ilustraciones de Ángel Baltasar.

247) Verte desnuda [varios autores], Madrid, Ediciones Temas de Hoy, Colección «Biblioteca erótica», n.ำ 18, 1992 [marzo], 160 páginas. 
248) Historias de la canalla. Las mejores anécdotas del periodismo español [varios autores], Madrid, Editorial Fundamentos, 1998 [marzo], 349 páginas. Edición de Max Bernáldez y Alonso Carretero Caballero.

249) Lo mejor de Hermano Lobo. Semanario de humor dentro de lo que cabe [varios autores], Madrid, Ediciones Temas de Hoy, 1999 [noviembre], 223 páginas.

250) El Quijote en el Café Gijón [varios autores], Madrid, Encarnación Fernández e Hijos, 2005 [diciembre], 624 páginas. Recopilación de José Bárcena.

251) 100 españoles y el sexo [varios autores], Barcelona, Random House Mondadori, 2009 [mayo], 825 páginas. Edición de David Barba.

\section{Antologías y selecciones de su obra}

252) La prosa y otra cosa (Antología), Madrid, Editorial El Gran Espectáculo, 1977 [diciembre], 83 páginas. Selección de Apuleyo Soto.

253) La rosa y el látigo. Noches, ninfas, fuegos, Madrid, Editorial Espasa Calpe, Colección «Austral», 1994 [noviembre], 330 páginas. Edición de Miguel García-Posada.

254) Francisco Umbral, premio Provincia de Valladolid 1994 a la trayectoria literaria, de Javier Villán, Valladolid, Diputación Provincial de Valladolid, Colección «Premios literarios», n. ㅇ 2, 1999 [enero], 97 páginas.

255) Los placeres y los días, Madrid, Fondo de Cultura Económica de España y Ediciones de la Universidad de Alcalá de Henares, Colección «Biblioteca Premios Cervantes», 2001 [abril], 174 páginas. Selección de Francisco Gómez-Porro.

256) Hojas de Madrid, Barcelona, Backlist, Colección «Backlist selectos», 2008 [abril], XIII + 1520 páginas. Prólogo de Miguel García-Posada.

257) Francisco Umbral y su tiempo [varios autores], Valladolid, Ayuntamiento de Valladolid, 2009 [mayo], 335 páginas. Edición de Santos Sanz Villanueva.

\section{Obra inédita ${ }^{2}$}

258) Los guantes de Rubén, 53 hojas.

259) Antimemorias, 23 hojas.

260) Autobiografía, 88 hojas.

261) Memorias incompletas, 20 hojas.

262) Memorial del fuego, 218 hojas.

263) Diario con guantes, 143 hojas.

264) Esnobismo y vanguardismo, 137 hojas.

\section{NOTAS}

1. Una exploración concienzuda sobre su biografía ha sido realizada por Anna Caballe en Francisco Umbral, el frío de una vida, Madrid, Espasa Calpe, Colección «Espasa hoy», 2004, 420 p.

2. Las referencias para este apartado están tomadas de la web oficial de la Fundación Francisco Umbral (http://www.fundacionumbral.com), consultada el 3 de mayo de 2011. 


\section{AUTOR}

JOSÉ LUIS CAMPAL FERNÁNDEZ

Real Instituto de Estudios Asturianos - Asturias, España 